\title{
PodCasting in het biomedisch onderwijs
}

\author{
H. van Rijen, A. Freriksen, M. van Emst, M. van Hoeij, M. Spinder, W. Hols, O. ten Cate
}

\section{Samenvatting}

Inleiding: Het digitaal opnemen en als PodCast aanbieden van hoorcolleges aan studenten wint aan populariteit. Er is echter weinig bekend over de invloed hiervan op het studiegedrag en op de effectiviteit. Deze retrospectieve observationele studie geeft antwoord op de volgende vragen: 1) Hoe beïnvloeden PodCasts de participatie in het contactonderwijs en het studiegedrag, en 2) Wat is het effect van het aanbieden van PodCasts op het studieresultaat. Materiaal en methoden: In de tweedejaarscursus Orgaansystemen van de opleiding Biomedische Wetenschappen van het Universitair Medisch Centrum Utrecht (UMC Utrecht) zijn vanaf het cursusjaar 2006/2007 hoorcolleges opgenomen en als PodCast aangeboden via een website. Het gebruik werd geëvalueerd via de reguliere cursusevaluatie.

Resultaten: De PodCasts werden als zeer nuttig ervaren en door 82-96\% van de studenten gebruikt om na het college nog eens te beluisteren. 12,5-26,5\% van de studenten gebruikt de Podcast als vervanging van het hoorcollege. Het aanbieden van PodCasts naast reguliere hoorcolleges leidde niet tot een hogere eindscore of andere tijdbesteding. De waardering voor de cursus ging wel sterk omhoog.

Discussie en conclusie: De PodCasts van hoorcolleges bij de cursus Orgaansystemen zijn intensief beluisterd zonder dat dit heeft geleid tot sterke afname van de participatie in de hoorcolleges zelf. De studenten gebruiken de PodCast met name als naluistergelegenheid. Er was geen duidelijk effect waarneembaar op het eindresultaat van de cursus. Om het effect van PodCasts naast reguliere hoorcolleges eenduidig vast te stellen, wordt onderzoek aanbevolen onder meer gecontroleerde omstandigheden. (Rijen $H$ van, Freriksen A, Emst M van, Hoeij M van, Spinder M, Hols W, Cate O ten. PodCasting in het biomedisch onderwijs. Tijdschrift voor Medisch Onderwijs 2010;29(5):284-292.)

\section{Inleiding}

PodCasts zijn audio- of videobestanden die via het internet worden verspreid en kunnen worden afgespeeld op computers en draagbare media, zoals de iPod van Apple of andere mediaspelers. PodCasting is een systeem waarin PodCasters bestanden beschikbaar stellen via het internet. ${ }^{1}$ Wanneer een gebruiker zich (gratis) abonneert op een PodCastpagina ${ }^{2}$ komt het bestand automatisch op de computers en mediaspelers van gebruikers terecht.

Computertechnologie heeft ook haar weg gevonden in het onderwijs, en het
PodCasten van hoorcolleges is hiervan een onderdeel, mede omdat met de juiste software en standaardhardware een opname relatief eenvoudig te realiseren is. ${ }^{3-4}$ In diverse artikelen worden de methodes beschreven en de mogelijkheden van het gebruik van PodCasting in het onderwijs benadrukt, ${ }^{5-22}$ maar in slechts enkele publicaties zijn de effecten hiervan op het leerproces gerapporteerd. ${ }^{23-25}$

Een veel gehoorde angst van docenten is dat het aanbieden van opgenomen hoorcolleges zou leiden tot een afname van het collegebezoek. Die angst is wel- 
licht gerechtvaardigd, aangezien uit een studie van McNulty et al. blijkt dat $42 \%$ van de studenten de opgenomen colleges gebruikt als vervanging van het college. ${ }^{24}$ Uit een studie van Billings-Gagliardi et al. kwam echter naar voren dat de beslissing om aanwezig te zijn bij een hoorcollege in $90 \%$ van de gevallen niet werd beïnvloed door het al dan niet beschikbaar zijn van PodCasts. ${ }^{25}$ Bij de overige $10 \%$ waren de PodCasts voor studenten juist wel aanleiding om naar de hoorcolleges te komen, omdat ze door de combinatie van hoorcollege én PodCasts de leerstof beter konden begrijpen. ${ }^{25}$

Een ander aspect is de invloed van PodCasts op het toetsresultaat. Uit een studie waarin een groep van studenten die een 25 minuten durend hoorcollege kreeg, werd vergeleken met een groep studenten die de PodCast kregen, kwam naar voren dat de PodCastgroep significant beter scoorde. ${ }^{23}$ Alhoewel beide groepen over handouts beschikten was de PodCastgroep in het voordeel, omdat de PodCast meerdere keren kon worden beluisterd. Een correlatie met PodCastgebruik en een slechter eindresultaat werd echter gevonden in de studie van McNulty et al. ${ }^{24}$ De auteurs vermoeden dat dit werd veroorzaakt door het feit dat met name de studenten die veel moeite hebben met het onderwerp, en dus laag scoren, de PodCasts gebruiken. In deze laatste studie kon echter niet worden vastgesteld of de laag scorende studenten wel naar het hoorcollege waren geweest en of de PodCast een slecht alternatief was voor het hoorcollege. De effecten van het aanbieden van PodCasts op het leerproces vallen in twee delen uiteen:

1. Hoe beïnvloeden PodCasts de participatie in het contactonderwijs en het studiegedrag?

2. Wat is het effect van het aanbieden van PodCasts op het studieresultaat?
Om een antwoord te krijgen op deze vragen zijn in de tweedejaarscursus Orgaansystemen van de opleiding Biomedische Wetenschappen van het Universitair Medisch Centrum Utrecht (UMC Utrecht) vanaf het cursusjaar 2006/2007 opnames van hoorcolleges aangeboden voor de diverse onderdelen. Screencasts (ingesproken opnames van het computerscherm) werden als PodCast naast de reguliere hoorcolleges aangeboden aan studenten als naluistergelegenheid. Het stond de studenten vrij om de PodCast als vervanging van het hoorcollege te gebruiken. De participatie en het studiegedrag van studenten en de studentwaardering voor de cursus werden door middel van evaluatieformulieren gemonitord en de effectiviteit op het eindresultaat kon worden getoetst aan de resultaten van de cursusjaren zonder PodCasts. De verwachting was dat de participatie in de hoorcolleges ongeveer gelijk zou blijven, dat de studenten de PodCasts voornamelijk als naluistergelegenheid zouden gebruiken en dat het eindresultaat van de cursus zou stijgen. Deze retrospectieve observationele studie geeft antwoord op de twee onderzoeksvragen en beschrijft de individuele ervaringen van studenten en docenten.

\section{Materiaal en methoden Achtergrond van de cursus Orgaansyste- men}

De cursus Orgaansystemen van de opleiding Biomedische Wetenschappen van het UMC Utrecht loopt in periode twee van het tweede studiejaar gedurende tien weken parallel aan een tweede cursus (Signaaltransductie of Biomembranen), evenredig verdeeld in de tijd. De cursus Orgaansystemen is opgebouwd uit drie basaal fysiologische delen, te weten Ademhaling, Hart en vaten en Nieren, en één integratief deel over hartfalen. Ieder basaal deel bevat vier hoorcolleges Orgaanfysio- 
logie en twee hoorcolleges: Anatomie en Microscopie. Het integratieve deel wordt ingeleid met twee hoorcolleges over de pathofysiologie van hartfalen.

Gedurende de cursus zijn er drie tussentoetsen (weegfactor: $3 \times 10 \%$ ) die bestaan uit dertig meerkeuzevragen en er is een beoordeelde presentatie over hartfalen (weegfactor: 10\%). De cursus wordt afgesloten met een eindtoets die bestaat uit vijf open vragen van de deelgebieden Ademhaling, Hart en vaten, Nieren, Anatomie en Microscopie (weegfactor: 60\%).

\section{Het opnemen en editen van PodCasts}

Voor het opnemen van PodCasts is met name gebruik gemaakt van 'screencasting'. In een geluidsarme ruimte wordt de screencapture software gestart en het college met de presentatiesoftware op het volledige computerscherm ingesproken. De muis wordt gebruikt als pointer. $\mathrm{Na}$ het inspreken van het college wordt de opname bijgewerkt, voorzien van een inleidende dia en jingle en geëxporteerd in $\mathrm{m} 4 \mathrm{v}$ formaat, waarna de opname geschikt is voor verspreiding.

Drie hoorcolleges zijn 'live' opgenomen. Hierbij is dezelfde software gebruikt als bij het afzonderlijk inspreken, behalve dat de docent een draadloze microfoon kreeg opgespeld.

\section{Verspreiding van PodCasts}

Om het downloaden en beluisteren van PodCasts te automatiseren is niet gekozen voor verspreiding via de reguliere elektronische leeromgeving Blackboard, maar via een website van de cursuscoördinator (Harold van Rijen): de PodCasts werden in de jaren 2006/2007 en 2007/2008 op de website van de afdeling Medische Fysiologie geplaatst en in de jaren 2008/2009 en 2009/2010 op mobileme.com van Apple. Alle benodigde software voor de studenten was gratis te verkrijgen. Een uitge- breide handleiding voor het installeren van software en voor het abonneren op de PodCast was voorhanden.

\section{Evaluatie}

Het gebruik van de PodCast is gedurende vier cursusjaren geëvalueerd middels de reguliere evaluatieformulieren van de sectie Kwaliteitszorg van het Expertisecentrum voor Onderwijs en Opleiding van het UMC Utrecht. In deze evaluatie waren zeven gesloten vragen opgenomen over PodCasting met ruimte voor opmerkingen.

\section{Statistische analyses}

De uitkomsten van de enquêtes en eindcijfers zijn weergegeven als het gemiddelde \pm de standaarddeviatie. Met een variantieanalyse (ANOVA) is per cursusonderdeel getoetst of er door de jaren heen verschil is tussen de gemiddelde cijfers.

\section{Resultaten}

\section{Invoering en gebruik PodCasts}

Het beschikbaar stellen van PodCasts van de hoorcolleges in de cursus Orgaansystemen is stapsgewijs ingevoerd. In het cursusjaar 2006/2007 zijn de vier hoorcolleges Cardiovasculaire fysiologie en twee hoorcolleges Hartfalen ingesproken en als PodCast aangeboden. ${ }^{26}$ In het jaar 2007/2008 zijn de PodCasts uitgebreid met de hoorcolleges Ademhalingsfysiologie, ${ }^{27}$ in 2008/2009 ingevoerd voor alle onderdelen, met uitzondering van enkele hoorcolleges Nieren, ${ }^{28}$ en in 2009/2010 zijn uiteindelijk alle hoorcolleges als PodCast aangeboden. ${ }^{29}$

Volgens de evaluaties was het gebruik in het eerste jaar $81,8 \%$ en is in de daaropvolgende jaren gestegen tot waardes rond de 95\% (zie Tabel 1). De studenten ervoeren het aanbieden van PodCasts als erg nuttig (4.6-4.9 op een schaal van 1-5) en technisch niet ingewikkeld (1.5-2.1 op een schaal van 1-5). 


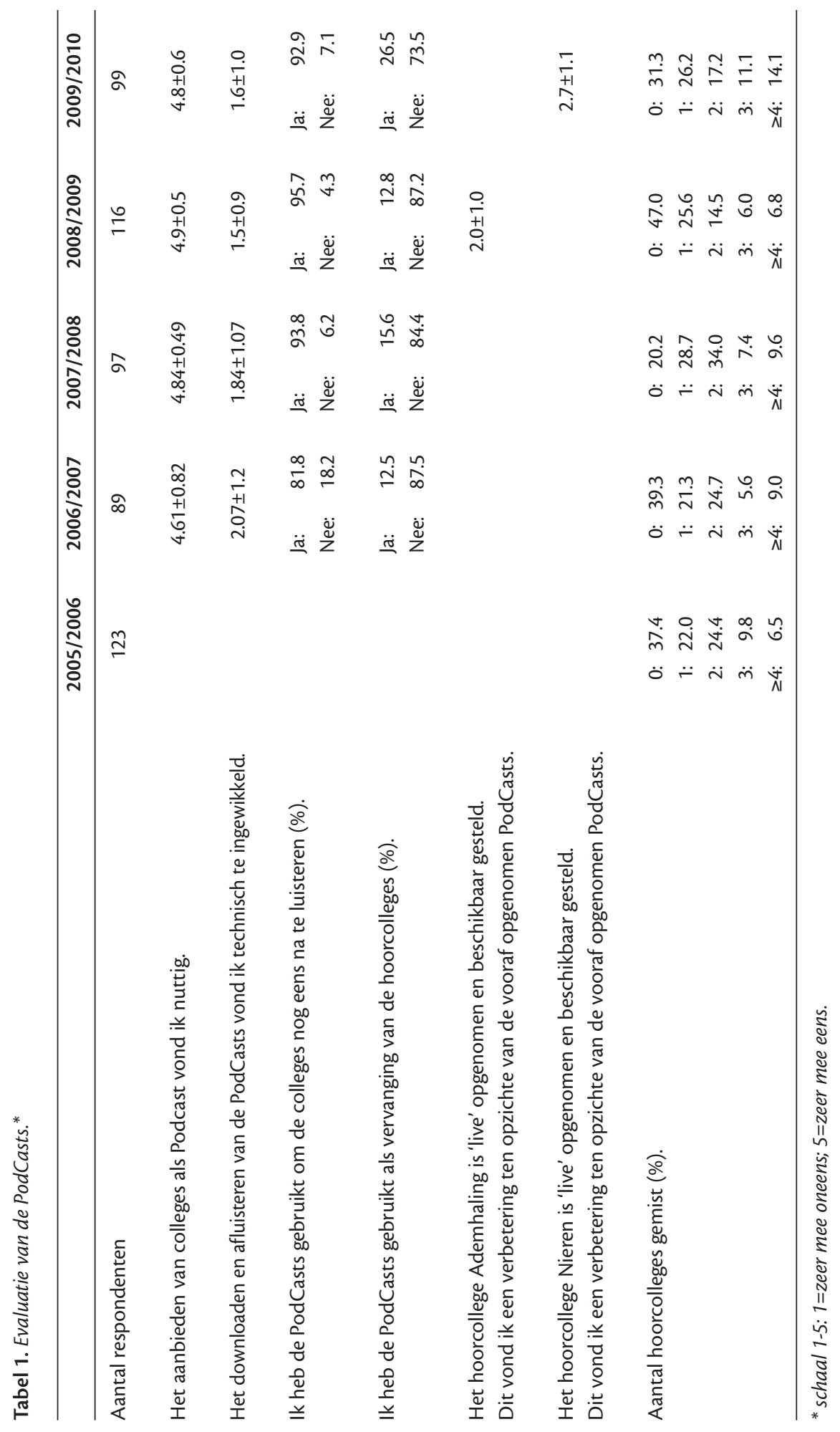


In de jaren 2006-2009 is het collegebezoek redelijk constant gebleven en gaf 13-16\% van de studenten aan de PodCasts te gebruiken als vervanging van hoorcolleges. In het jaar 2009/2010 was dit hoger en gaf $27 \%$ van de studenten aan de PodCasts als vervanging van de hoorcolleges te hebben gebruikt. In de evaluaties werd eveneens gevraagd naar het collegebezoek zelf (zie Tabel 1). Gemiddeld volgde in de jaren 2005-2010 $35 \%$ van de studenten alle colleges, miste $25 \%$ één colege, $25 \%$ twee, $8 \%$ drie en $9 \%$ vier of meer colleges. Er is geen duidelijke trend voor verhoogde afwezigheid in relatie tot de beschikbaarheid van de PodCasts, al was het aantal studenten dat drie of meer colleges miste in het jaar 2009/2010 hoger.

In 2008/2009 is één van de hoorcolleges Ademhaling 'live' opgenomen. Deze werd naast een apart ingesproken versie aan de studenten beschikbaar gesteld. ${ }^{30}$ De studenten waren van mening dat deze variant geen meerwaarde had ten opzichte van de ingesproken variant $(2.0 \pm 1.0)$. In het jaar $2009 / 2010$ is de helft van de hoorcolleges Nieren 'live' opgenomen door de docent zelf, zonder dat er een vooraf ingesproken variant als alternatief werd aangeboden. Deze werden in de evaluatie als gelijkwaardig aan de vooraf ingesproken varianten beoordeeld $(2.7 \pm 1.1)$. Uit de individuele opmerkingen in de evaluatie kwam wel naar voren dat 'live' opgenomen colleges wat onrustiger zijn om naar te luisteren en dat vragen uit de zaal niet te verstaan zijn, tenzij de docent ze herhaalt.

\section{Effectiviteit van PodCasts}

Tabel 2 laat de resultaten zien van de verschillende onderdelen van de eindtoets Orgaansystemen: het eindcijfer van de cursus, het slagingspercentage, de tijdsbesteding en de studentenbeoordeling. In de tabel geven de grijze velden aan van welke onderdelen de hoorcolleges als PodCast zijn aangeboden.
Wanneer we de gemiddelde deelcijfers per onderdeel vergelijken tussen de jaren zonder en de jaren met PodCast, zien we voor Hart en vaten een significante stijging van het deelcijfer van 6.2 naar 7.0, maar voor Anatomie een significante daling van 7.3 naar 6.7. Wat betreft het eindcijfer van de gehele cursus zijn de afgelopen jaren geen verschillen gevonden. Het slagingspercentage laat evenmin een duidelijke relatie zien met het al dan niet aanwezig zijn van PodCasts. Wel waren er verschillen te zien in de hoeveelheid tijd die de studenten per week aan het blok besteed hebben, echter niet tussen 20052008 (gedeeltelijke PodCasting: 16.0 uur) en tussen 2008-2010 (gehele PodCasting: 16.0 uur). De studentwaardering voor de cursus is gaandeweg de jaren wel sterk opgelopen.

\section{Discussie}

\section{Invoering en gebruik PodCasts}

Van docenten werd gevraagd de hoorcolleges apart in te spreken, zonder onrust van de collegezaal, zodat een hoge kwaliteit video en audio kon worden gegarandeerd. Een aantal docenten zag tegen deze extra inspanning op of had er gewoonweg de tijd niet voor. Andere docenten vonden het juist een prettig idee dat zij niet geconfronteerd werden met bijvoorbeeld versprekingen tijdens een 'live' opgenomen hoorcollege. Dit heeft er toe geleid dat de volledige set van PodCasts pas na drie jaar compleet was. Om voor de betreffende docent de extra tijdsinvestering te omzeilen is een aantal colleges van het onderdeel Nieren in het jaar 2009/2010 'live' opgenomen. Alhoewel de studenten dit geen verbetering vonden, werd het ook zeker niet als een mindere variant beoordeeld. 'Live' opnemen zou dus de factor tijd als drempel voor de docenten kunnen wegnemen zonder verlies van kwaliteit voor de student. De herge- 


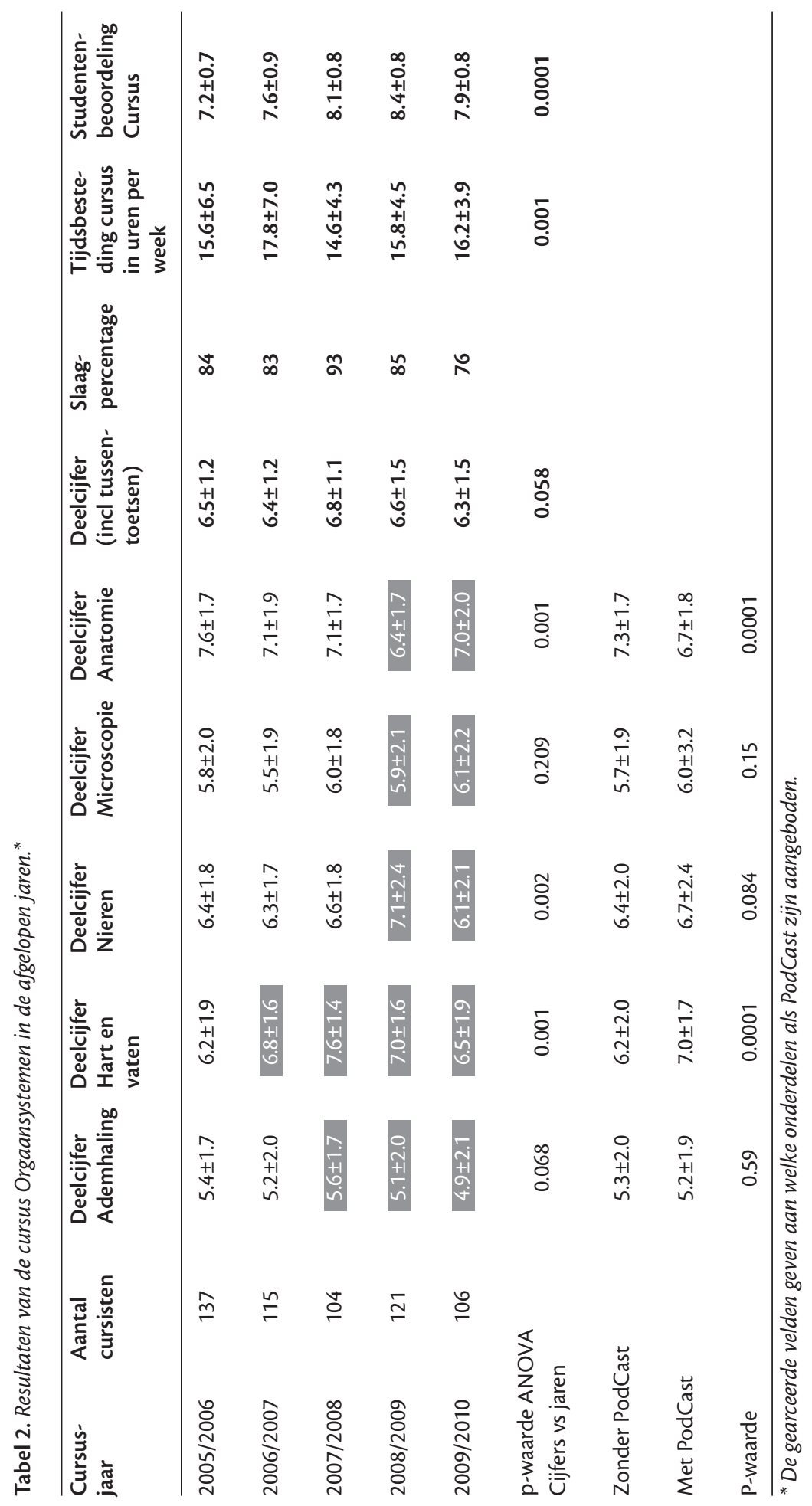


bruikwaarde van een PodCast wordt door ons ingeschat op minimaal twee jaar.

Het gebruik van de PodCasts was enorm groot. Meer dan 95\% van de studenten heeft in de laatste jaren de PodCasts gebruikt om de colleges nog eens na te luisteren. Technische beperkingen hebben hierin geen rol van betekenis gespeeld. Uit de individuele opmerkingen van de studenten uit de evaluaties blijkt dat de PodCasts met name worden gebruikt om het college nog eens na te luisteren:

\section{"De PodCasts zijn heel fijn om alles nog eens na te luisteren. Ook hoef je tijdens de colleges zo minder hard te schrijven en kun je beter opletten". ${ }^{31}$}

Dit komt overeen met uitkomsten van andere studies, waaruit naar voren komt dat PodCasts met name werden gebruikt om het college nog eens na te luisteren en om het examen voor te bereiden. ${ }^{25}$ Ondanks deze extra studieactiviteit is de totale tijdsinvestering constant gebleven. Het luisteren naar PodCasts gaat dus ten koste van andere studieactiviteiten. Welke studieactiviteiten dat zijn is hier niet onderzocht, maar een mogelijkheid zou kunnen zijn dat studenten hun aantekeningen nalopen aan de hand van de PodCasts en niet aan de hand van hun studieboeken.

De angst van docenten dat door het aanbieden van PodCasts van hoorcolleges het collegebezoek terug zou lopen, bleek tijdens deze cursus slechts gedeeltelijk terecht. Alhoewel 15-25\% van de studenten aangaf de PodCasts als vervanging te gebruiken, was er geen duidelijke trend te zien in het collegebezoek. De laagste opkomst betrof zeker niet de jaren 20082010 , toen PodCasts volledig voor handen waren. In 2008/2009 was de participatie het hoogst en in 2009/2010 het laagst. Uit een studie van McNulty et al. blijkt dat de participatie tot onder de $58 \%$ daalt na invoering van PodCasts. ${ }^{24}$ Een dergelijk sterke daling is in onze cursus Orgaansystemen zeker niet gezien.

\section{Effectiviteit van PodCasts}

Het effect van de PodCasts op het cijfer voor de toetsing en op het eindresultaat is niet eenduidig. Het al dan niet beschikbaar zijn van een PodCast om het college nog eens te kunnen naluisteren heeft niet geleid tot een betere score voor de afzonderlijke onderdelen in de volle breedte noch tot een hoger eindcijfer voor de cursus als geheel; ook heeft het niet geleid tot een verhoogd slagingspercentage. Voor twee onderdelen, Hart en vaten en Anatomie, is respectievelijk significant hoger en lager gescoord in de periode waarin PodCasts voorhanden waren. De docenten voor deze onderdelen zijn gedurende de vijf jaren niet gewisseld, maar wisselingen in de moeilijkheidsgraad van het tentamen of een andere samenstelling van de studentenpopulatie zouden hiervoor een verklaring kunnen zijn. In onze studie heeft het beschikbaar stellen van PodCasts dus niet geleid tot een slechter ${ }^{24}$ of beter $^{23}$ eindresultaat.

De cursusorganisatie en -inhoud is in de afgelopen jaren vrijwel identiek gebleven en alleen voor het onderdeel Nieren zijn er docentenwisselingen geweest. De waardering voor de cursus is wel sterk toegenomen in de jaren dat PodCasts werden aangeboden. Uit deze studie komt niet duidelijk naar voren welke factor heeft gezorgd voor een betere waardering van de cursus. Een zeer veel voorkomende opmerking in de evaluatie is wel dat studenten het aanbieden van PodCasts als een enorm nuttige en welkome aanvulling op het contactonderwijs ervaren binnen de cursus Orgaansystemen. Verder is er een sterke roep om PodCasts bij alle vakken in te voeren. 


\section{Conclusie}

De PodCasts van hoorcolleges bij de cursus Orgaansystemen worden intensief gebruikt, zonder dat dit heeft geleid tot sterke afname van de participatie in de hoorcolleges zelf. De studenten gebruiken de PodCast dus met name als naluistergelegenheid. Er was geen duidelijk effect waarneembaar op het eindresultaat van de cursus. Om het effect van PodCasts naast reguliere hoorcolleges eenduidig vast te stellen, zal er onderzoek moeten worden gedaan onder gecontroleerde omstandigheden.

\section{Literatuur}

1. RSS-Wikipedia, "RSS," http://en.wikipedia.org/ wiki/RSS\#History.

2. iTunes@Apple.com, “iTunes," http://www.apple.com/ itunes/.

3. Dankbaar MEW. De effectiviteit van e-learning en de implementatie in het medisch onderwijs. Tijdschrift voor Medisch Onderwijs 2009;28(5): 212-222. [The effectiveness of e-learning and its implementation in medical education. Netherlands Journal of Medical Education 2009;28(5):212-222].

4. Ruiz JG et al. The impact of E-learning in medical education. Acad Med 2006;81(3):207-212.

5. Abreu DV et al. Podcasting: contemporary patient education. Ear Nose Throat J 2008; 87 (4):208, 210-201

6. Alikhan A et al. Podcasting in dermatology education. J Dermatolog Treat 2009,1-7.

7. Corl FM et al. Internet-based dissemination of educational video presentations: a primer in video podcasting. Am J Roentgenol 2008; 191 no. 1,W23-27.

8. Forbes MO, Hickey MT. Podcasting: implementation and evaluation in an undergraduate nursing program. Nurse Educ 2008; 33 (5):224-227.

9. Jham BC et al. Joining the podcast revolution. J Dent Educ 2008;72(3): 278-281.

10. Johnson L, Grayden S. Podcasts--an emerging form of digital publishing. Int J Comput Dent 2006; 9(3): 205-218.

11. Kennedy G et al. Net Generation' medical students: technological experiences of pre-clinical and clinical students. Med Teach 2008; 30 (1):10-16.

12. Maag M. Podcasting and MP3 players: emerging education technologies. Comput Inform Nurs 2006; 24(1):9-13.

13. Palmer EJ, Devitt PG. A method for creating interactive content for the iPod, and its potential use as a learning tool: technical advances. BMC Med Educ 2007; 7: 32.

14. Ragon B, Looney RP. Podcasting at the University of Virginia Claude Moore Health Sciences Library. Med Ref Serv Q 2007; 26(1):17-26.

15. Reynolds PA et al. Webcasting: casting the web more widely. Br Dent J 2008; 204(3):145-149.

16. Rowell MR et al. Internet-based dissemination of educational audiocasts: a primer in podcasting how to do it. Am J Roentgenol 2006; 186(6):17921796.

17. Savel RH et al. The iCritical care podcast: a novel medium for critical care communication and education. J Am Med Inform Assoc 2007; 14 (1):94-99.

18. Shantikumar S. From lecture theatre to portable media: students' perceptions of an enhanced podcast for revision. Med Teach 2008:1-4.

19. Trelease RB. Diffusion of innovations: smartphones and wireless anatomy learning resources. Anat Sci Educ 2008; 1(6):233-239.

20. Tripp JS, et al. Academic podcasting: quality media delivery. AMIA Annu Symp Proc 2006: 1125 .

21. Walton $\mathrm{G}$ et al. Using mobile technologies to give health students access to learning resources in the UK community setting. Health Info Libr J 2005;22 Suppl2:51-65.

22. Whitehead DE et al. Not just music but medicine. Podcasting surgical procedures in otolaryngology. Clin Otolaryngol 2007;32(1): 3-6.

23. McKinney $\mathrm{D}$ et al. iTunes University and the classroom: Can podcasts replace Professors? Computers and Education 2009; 52:617-623.

24. McNulty JA et al. An analysis of lecture video utilization in undergraduate medical education: associations with performance in the courses. BMC Med Educ 2009; 6.

25. Billings-Gagliardi S, Mazor KM. Student decisions about lecture attendance: do electronic course materials matter? Acad Med 2007; 82(10 Suppl):S73-76.

26. Orgaansystemen, 2006-2007; http://www.physiol. med.uu.nl/orgaansystemen/Podcasts/Podcasts.html.

27. Orgaansystemen, 2007-2008; http://www.physiol. med.uu.nl/orgaansyste men0708/.

28. Orgaansystemen, 2008-2009; http://web.me.com/ haroldvanrijen/Orgaansystemen0809/.

29. Orgaansystemen, 2009-2010; http://web.me.com/ haroldvanrijen/Orgaansystemen0910/.

30. Ademhaling, LC, LectureNet College Ademhaling 2008; http://131.211.194.110/site1/Viewer/?peid=6 6b42a00509046cdafd62f5283da3885.

31. Expertisecentrum-dOO, Evaluatie Orgaansystemen, 2008-2009. 
De auteurs:

Dr. H. van Rijen is universitair hoofddocent, afdeling Medische Fysiologie, Divisie Hart \& Longen, Universitair Medisch Centrum Utrecht.

Drs. A. Freriksen is universitair docent, Onderwijsinstituut Biologie, Faculteit Bètawetenschappen, Universiteit Utrecht.

Dr. M.G. van Emst is universitair docent, departement Pathobiologie - divisie Anatomie en Fysiologie, Faculteit Diergeneeskunde, Universiteit Utrecht.

Drs. M. van Hoeij is universitair docent, afdeling Celbiologie, divisie Biomedische Genetica, UMC Utrecht.

Drs. M. Spinder is anatoom, afdeling Aanatomie, divisie Heelkundige Specialismen, UMC Utrecht.

Drs. W.P.M. Hols-Elders is programmaleider Onderwijstechnologie, Expertisecentrum voor Onderwijs en Opleiding, UMC Utrecht.

Prof. dr. O. ten Cate is hoogleraar medische onderwijskunde, directeur Expertisecentrum voor Onderwijs en Opleiding, UMC Utrecht.

\section{Correspondentieadres:}

Dr. H. van Rijen, UMCU afd. Medische Fysiologie, Yalelaan 50,3584 CM Utrecht.E-mail:h.v.m.vanrijen@ umcutrecht.nl

Belangenconflict: geen gemeld

Financiële ondersteuning: geen gemeld

\section{Summary}

Introduction: The electronic distribution of classroom lecture recordings as PodCasts is getting more and more popular. However, fairly little is known about the effects of PodCasts on study behaviour and results. This retrospective observational study focused on two research questions: 1. How does the availability of PodCasts influence classroom lecture attendance and study behaviour? and 2. How does the availability of PodCasts influence study results?

Materials and methods: During the second year course on 'Organ Systems' of the programme in Biomedical Sciences of the University Medical Center Utrecht, classroom lectures have been digitally recorded and distributed on a website since 2006/2007. PodCast usage was evaluated in the regular end-of-course evaluation.

Results: The PodCasts were experienced as very useful and viewed by 82-96\% of the students. 12.5-26.5\% of the students used the PodCasts to replace one or more classroom lectures. The majority used them to review lectures they had attended. The availability of PodCasts did not increase student grades or study time. However, course ratings went up appreciably as a result of the PodCasts.

Discussion and conclusion: Despite intensive use by students, PodCasts did not strongly affect lecture attendance. Students mainly use PodCasts to review attended lectures. Students' final course grades showed no clear change. Further research under controlled conditions will be needed to more exactly determine the specific effects of PodCasts on students' study behaviour and results. (Rijen H van, Freriksen A, Emst M van, Hoeij M van, Spinder M, Hols W, Cate O ten. PodCasting in biomedical education. Netherlands Journal of Medical Education 2010;29(5):284-292.) 